\title{
Give a voice to the voiceless
}

\author{
Kamran Abbasi executive editor
}

The BMJ

Rudolf Virchow's investigation of a typhus epidemic in 1848 identified a root cause: "The power of the aristocracy, propped up by the church." Big business is today's aristocracy, politicians and the state today's church. In society's pursuit of wealth and profit, it is poor people who carry the greatest burden of disease, whose deaths are most likely when fire engulfs a tower block, the levees break in New Orleans, or a Titanic sinks.

After last week's fire in London's Grenfell Tower Martin McKee recalls Virchow to urge us not to ignore the political and commercial determinants of public health (doi:10.1136/bmj. j2966). Inadequate safety measures, despite warnings from residents, contributed to and probably caused 79 people to be dead or missing. This was a political failure leading to avoidable deaths and, says McKee, "it is impossible to achieve a comprehensive understanding of events such as Grenfell Tower without confronting the political determinants of health and challenging the forces that shape them."

One solution might be to put an end to high rise living. An area might be regenerated by demolishing a "sink estate" that includes high rise buildings and replacing it with luxury apartments and low rise, affordable housing. But this would be a form of "social cleansing," explains Anna Minton (doi:10. $1136 / \mathrm{bmj} . j 2981$ ). The volume of new affordable housing is invariably too small, with a net loss of 8000 social homes in
London in the past decade. Indeed, most residents "love" their tower blocks, but their experience is sullied by forces outside their control, from broken lifts to lack of security. The issue is less with the tower blocks themselves and more closely related to socioeconomic factors. "At a time of huge worry and uncertainty," writes Minton, "threats to demolish people's homes cannot be helping."

Inequality and the vulnerabilities of poor people find an echo in our research section. Bochen Cao and colleagues (doi:10. 1136/bmj.j2765) grouped countries by Human Development Index and examined the effect of variation in cancer death rates on longevity. Countries with the greatest resources benefited most in life expectancy as a direct result of improving cancer mortality. In an accompanying commentary (doi:10.1136/bmj. j2920), Mary Louise Tørring acknowledges the inequalities at play, and proposes priority funding for poor countries and for women, but wonders whether these new findings "might also prompt us to think more about cancer as a natural ceiling on human longevity rather than as a rising epidemic."

A key message here, from a devastating fire in a London tower block to patchy global progress in longevity, is that health professionals have a responsibility to ensure that the weak are not silenced, ignored, or discounted. We must, in the words of McKee, with a nod to Virchow, give voice to the voiceless. 